\title{
Effects of wall vibration on particle deposition and reentrainment in aerosol flow
}

\section{AUTHOR(S):}

Theerachaisupakij, Woraporn; Matsusaka, Shuji; Kataoka, Masahiko; Masuda, Hiroaki

\section{CITATION:}

Theerachaisupakij, Woraporn ... [et al]. Effects of wall vibration on particle deposition and reentrainment in aerosol flow. Advanced Powder Technology 2002, 13(3): 287-300

\section{ISSUE DATE:}

2002

URL:

http://hdl.handle.net/2433/198912

\section{RIGHT:}

(c) Brill.; This is not the published version. Please cite only the published version.; この論文は出版社版でありません。引用の際には出版社版を ご確認ご利用ください。 
Effects of wall vibration on particle deposition and reentrainment in aerosol flow

WORAPORN THEERACHAISUPAKIJ, SHUJI MATSUSAKA*, MASAHIKO KATAOKA and HIROAKI MASUDA

Department of Chemical Engineering, Kyoto University, Kyoto 606-8501 Japan

\begin{abstract}
The simultaneous phenomenon of particle deposition and reentrainment on a vibrating wall has been studied experimentally. Aerosols that were generated by dispersing alumina powder, of size 3.8-12.5 $\mu \mathrm{m}$ mass median diameter, were transported into a vertical glass tube equipped with a vibration motor. The formation process of the particle deposition layer in the tube was observed through a digital video camera with a zoom lens. The experimental results showed that wall vibration was effective to enhance particle reentrainment. Critical flow velocity for the case of no particle layer formation decreased with increasing vibration acceleration and/or particle diameter. In contrast, at a velocity below the critical value, the wall vibration increased the amount of particles deposited on the wall. The critical condition for no particle layer formation under wall vibration was explained using a moment balance model.
\end{abstract}

Keywords: Vibration; particle deposition; reentrainment; aerosol flow; moment balance

* To whom correspondence should be addressed. 


\section{NOMENCLATURE}

$A$

Hamaker constant (J)

$D$

diameter in (8) $\left(=D_{1} D_{2} /\left(D_{1}+D_{2}\right)\right) \quad(\mathrm{m})$

$D_{\text {ag }}$

diameter of aggregate (m)

$D_{\mathrm{p}} \quad$ particle diameter (m)

$D_{\mathrm{p} 50} \quad$ mass median diameter of particles (m)

$D_{\mathrm{t}} \quad$ tube diameter $(\mathrm{m})$

E Young's modulus (Pa)

$F_{\mathrm{a}} \quad$ adhesive force between particle and wall

(N)

$F_{\mathrm{C}} \quad$ maximum collision force $(\mathrm{N})$

$F_{\mathrm{d}} \quad$ aerodynamic drag force $(\mathrm{N})$

$F_{\mathrm{g}} \quad$ gravitational force $(\mathrm{N})$

$F_{\mathrm{v}} \quad$ force caused by wall vibration $(\mathrm{N})$

$g \quad$ gravitational acceleration $\left(\mathrm{m} / \mathrm{s}^{2}\right)$

$k \quad=\left(1-v_{1}^{2}\right) / E_{1}+\left(1-v_{2}^{2}\right) / E_{2} \quad(1 / \mathrm{Pa})$

$k_{0} \quad=D_{\text {ag }} / D_{\mathrm{p}} \quad(-)$

$k_{1} \quad$ constant in (13) $\quad\left(\mathrm{m}^{43 / 10} / \mathrm{s}^{21 / 10}\right)$

$k_{2} \quad$ constant in (13) $\quad\left(\mathrm{m}^{13 / 10} / \mathrm{s}^{1 / 10}\right)$

$M_{\mathrm{a}} \quad$ adhesion moment $(\mathrm{N} \cdot \mathrm{m})$

$M_{\mathrm{c}} \quad$ moment caused by particle collision $\quad(\mathrm{N} \cdot \mathrm{m})$

M $\quad$ aerodynamic drag moment $\quad(\mathrm{N} \cdot \mathrm{m})$

$M_{\mathrm{g}} \quad$ gravity moment $\quad(\mathrm{N} \cdot \mathrm{m})$

$M_{\mathrm{v}} \quad$ moment caused by wall vibration $\quad(\mathrm{N} \cdot \mathrm{m})$

$m \quad$ mass in (8) $\left(=m_{1} m_{2} /\left(m_{1}+m_{2}\right)\right) \quad(\mathrm{kg})$ 


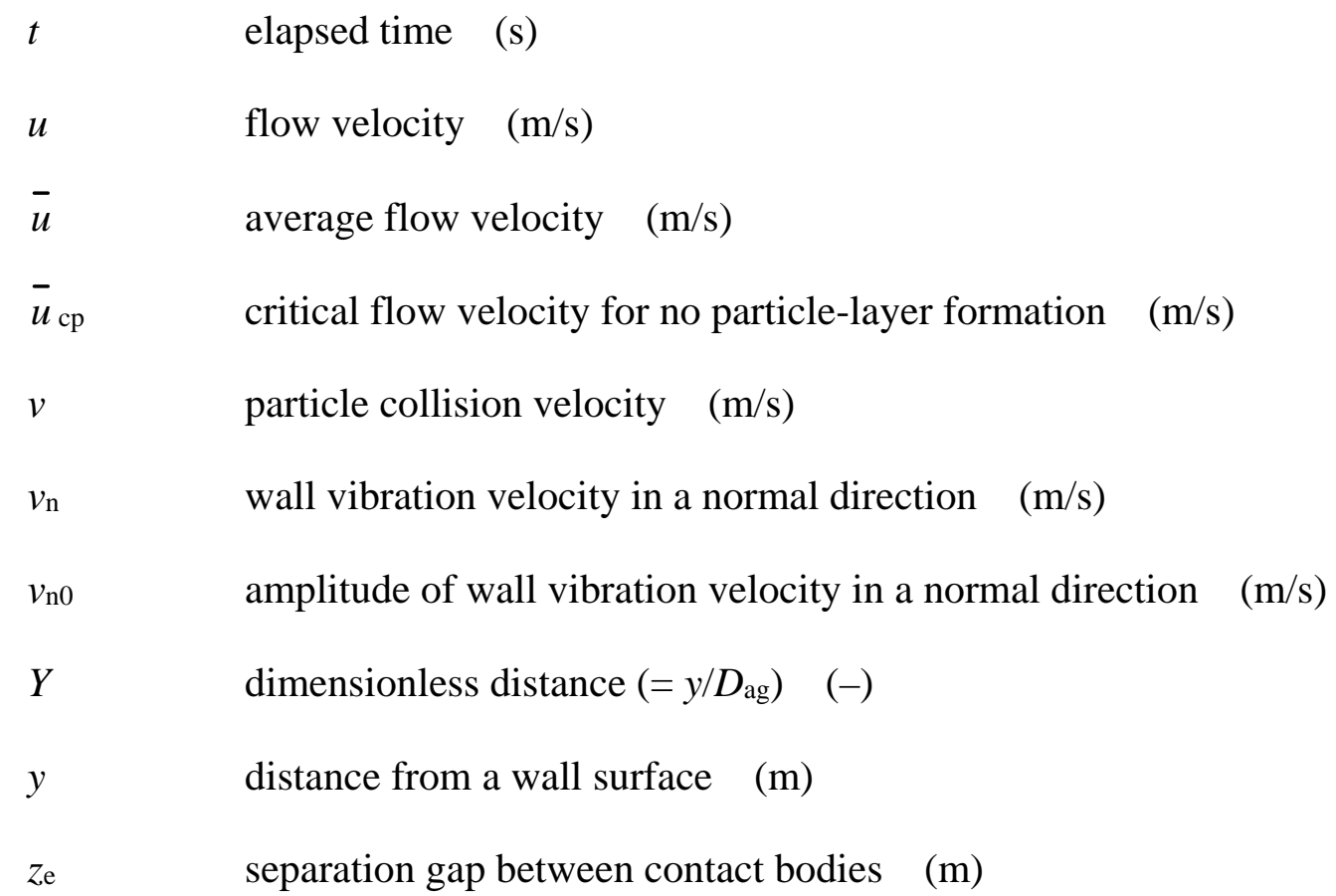

\section{Greek}

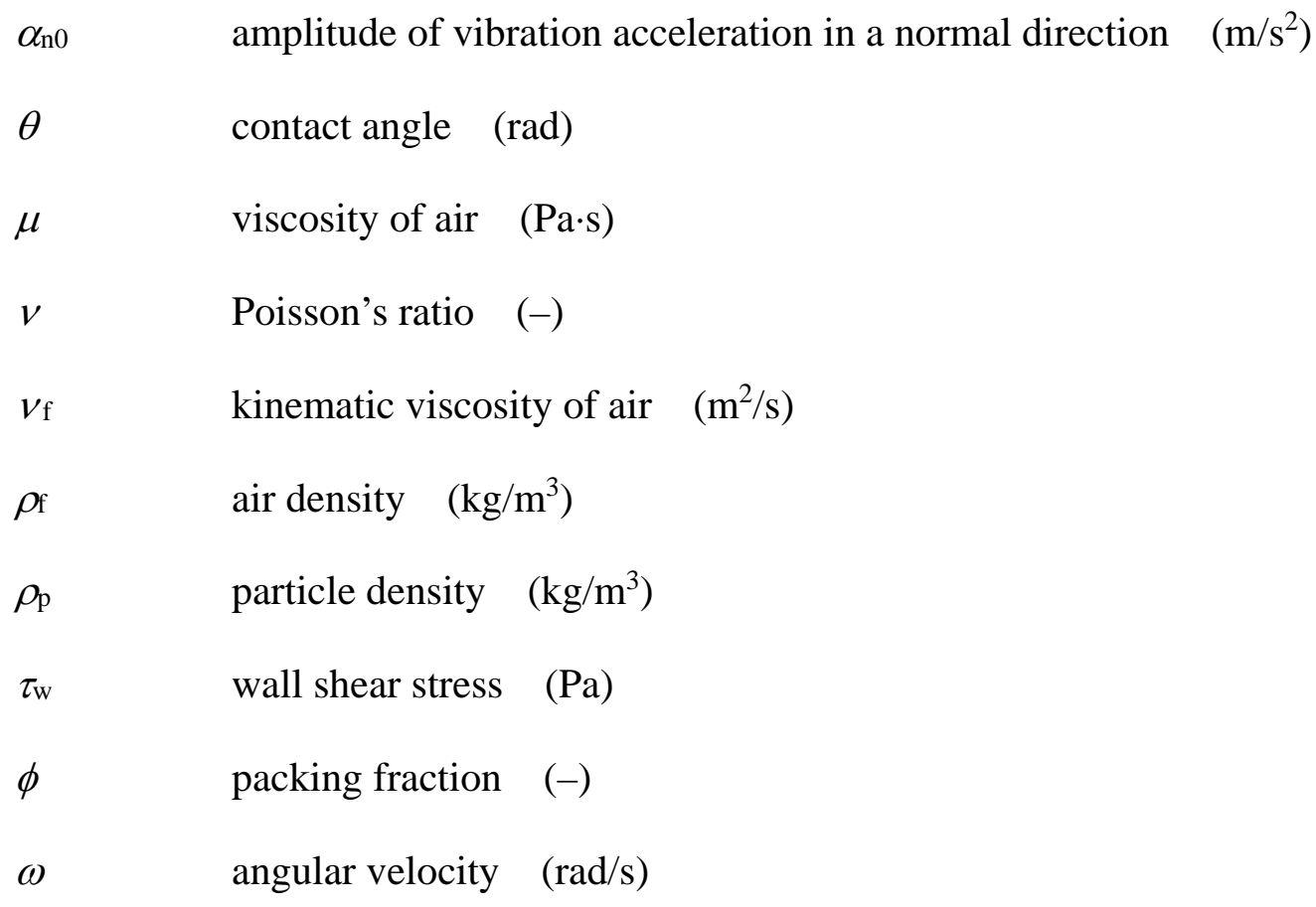




\section{INTRODUCTION}

Particle deposition and reentrainment are related to numerous engineering applications such as pneumatic transport, dust collection, atmospheric pollution, control of micro-contamination and design of gas-solids reactors. It is important in these operations to accurately estimate and control both the particle deposition and reentrainment.

Research on particle deposition in a turbulent aerosol flow has been carried out extensively [1-6]; in particular, the particle deposition rate was studied in detail. For particle reentrainment, models for the separation mechanism [7-11] and particle reentrainment rate [12-16] have been studied, in which the reentrainment was treated as being independent of particle deposition. However, under actual conditions, reentrainment is closely related to particle deposition and often occurs simultaneously. Thus, several attempts to combine both these concepts into a model were made $[17,18]$, where the deposition and reentrainment are restricted to the phenomena for primary particles. In powder handling, a particle deposition layer is often formed in a pneumatic pipeline and small aggregates are mainly reentrained from the deposition layer. In recent years, the formation process of the particle deposition layer in turbulent aerosol flow has been studied under various conditions [19-26].

In the present work, we focus on enhancement of particle reentrainment and removal of the particle deposition layer under wall vibration, and study the effect of the vibration on the simultaneous particle deposition and reentrainment. Furthermore, the criterion for no particle layer formation is explained using a moment balance model.

\section{EXPERIMENTAL APPARATUS AND PROCEDURES}


Figure 1 shows a schematic diagram of the experimental apparatus. Powders used in the experiment were alumina, of size 3.8-12.5 $\mu \mathrm{m}$ mass median diameter, the geometric standard deviations were $1.5 \pm 0.1$, and the particle density was $4000 \mathrm{~kg} / \mathrm{m}^{3}$. The powders were dried at $110^{\circ} \mathrm{C}$ over $12 \mathrm{~h}$ and cooled down to room temperature in a desiccator. The powder that was continuously discharged from a table feeder (Sankyo Piotech; MFOV-1) was dispersed into airflow (10\% RH) through two ejectors (Japan Pisco; VHH 12-801 J). The aerosol concentration was in the range of $0.02-0.05 \mathrm{~kg} / \mathrm{m}^{3}$. The test section was a glass tube, $6 \mathrm{~mm}$ inner diameter and $1000 \mathrm{~mm}$ long, which was installed vertically. A small vibration motor (Akizuki Denshi; CM5M) was fixed on the glass tube $500 \mathrm{~mm}$ away from its inlet and allowed to oscillate horizontally. A laser Doppler method was used to analyze the wall vibration and the state of the deposition layer formed in the tube was observed through a digital video camera with a zoom lens of the maximum magnification of $\times 140$.

\section{RESULTS AND DISCUSSION}

\subsection{Particle deposition layer formed on a non-vibrating wall}

When the particle deposition was in equilibrium with the reentrainment, the amount of particles deposited on the wall became constant and the apparent state of the particle deposition layer was not changed. The equilibrium state was classified into (i) a continuous (filmy) deposition layer and (ii) a striped deposition layer. Figure 2 shows a constitutional diagram of the particle deposition layer as a function of average flow velocity and particle diameter. A line with black symbols indicates the boundary between the two regions of the filmy and striped deposition layer. A line with white symbols indicates the critical condition for no particle layer formation. In the region 
where there was no deposition layer, there were no aggregates, but small primary particles were observed adhering to the wall. When the flow velocity was increased slowly, the filmy deposition layer changed into the striped deposition layer and finally disappeared due to the reentrainment. Hence, the state of the striped deposition layer could be a clue to evaluate the critical condition for no particle layer formation.

\subsection{Effects of wall vibration on the particle deposition layer}

Figure 3 shows wall vibration velocities normal to an observed wall surface $v_{n}$. The waveforms that were measured with the laser Doppler analyzer were sinusoidal. From the waveforms, the amplitudes of vibration acceleration $\alpha_{\mathrm{n} 0}\left(=v_{\mathrm{n} 0} \omega\right)$ can be obtained.

Figure 4 shows the transition states of the particle deposition layer at different amplitudes of vibration acceleration. The striped deposition layer at $t=0 \mathrm{~s}$ was in equilibrium under non-vibration. After starting a vibration of $\alpha_{\mathrm{n} 0}=590 \mathrm{~m} / \mathrm{s}^{2}$, the amount of particles deposited on the wall decreased (see Fig. 4a). However, the particle deposition layer still remained partially on the wall after $150 \mathrm{~s}$. For $\alpha_{\mathrm{n} 0}=1070$ $\mathrm{m} / \mathrm{s}^{2}$, the striped deposition layer disappeared within $20 \mathrm{~s}$ (see Fig. $4 \mathrm{~b}$ ). When the experiment was started from no deposition layer, the final state was the same as that in Fig. 4, i.e. the equilibrium state of the particle deposition layer was independent of the initial condition.

Figure 5 shows the transition states of the particle deposition layer at different average flow velocities. For $\bar{u}=16.1 \mathrm{~m} / \mathrm{s}$, the amount of deposited particles became smaller with elapsed time and ultimately they disappeared from the wall surface (see Fig. 5a). In addition, the striped deposition layer that formed on the vibrating wall moved downstream steadily. The same phenomenon occurs on the non-vibrating wall 
$[20,21,23]$. This is explained as follows: (i) small aggregates are reentrained from the front part of the striped deposition layer due to the aerodynamic drag and the collision of aerosol particles with the deposition layer, and (ii) aerosol particles deposit on the back part. The moving velocity of the striped deposition layer is controlled by the rates of particle collision and deposition, which depend on particle size, flow velocity and aerosol particle concentration.

However, the wall vibration was not always effective to remove the deposition layer. For $\bar{u}=14.4 \mathrm{~m} / \mathrm{s}$, the amount of particles deposited on the wall increased with elapsed time (see Fig. 5b), i.e. a new filmy deposition layer was formed over the striped deposition layer. When the vibration stopped, the deposition layer transformed into the striped deposition layer. From these results, it was found that the wall vibration plays two opposite roles, i.e. (i) to increase the separation force and (ii) to increase the particle deposition rate due to active capture of aerosol particles. When the latter dominates the simultaneous phenomenon of particle deposition and reentrainment, the filmy deposition layer is formed.

\subsection{Theoretical model for the reentrainment of a small aggregate from a wall surface}

In general, small primary particles deposited on a wall surface are difficult to reentrain. As aerosol particles deposit accidentally on the particles adhering to the wall, they form small aggregates, which can transform into a striped deposition layer or could disappear. Thus, we considered that the existence of small aggregates is related to a critical state for particle layer formation

Figure 6 illustrates the forces acting on the aggregate on the vibrating wall. It is assumed that: (i) the spherical aggregate has a diameter of $D_{\text {ag, }}$ which is $k_{0}$ times as 
large as that of the primary particle $D_{\mathrm{p}}$, and contacts with the wall at an angle of $\theta$, (ii) the aggregate is submerged in a viscous sublayer where the shear flow is steady and not disturbed by the aggregate, and (iii) collision velocity of an aerosol particle is equal to that of the airflow at the same height level. In the present model, we apply the concept of a moment balance [7-11, 15, 23], and take into account forces of adhesion, gravity, aerodynamic drag, particle collision and vibration.

The adhesion moment $M_{\mathrm{a}}$ is represented by:

$$
M_{\mathrm{a}}=F_{\mathrm{a}} D_{\mathrm{ag}} \sin \theta
$$

where $F_{\mathrm{a}}$ is the adhesive force. In general, van der Waals force, liquid bridge force and electrostatic force act on the contacting bodies. However, the liquid bridge force and the electrostatic force are negligible in our experiment because of low humidity $(\approx$ $10 \% \mathrm{RH})$ and small particle charges $(<1 \mathrm{mC} / \mathrm{kg})$. The adhesive force based on the van der Waals interaction acting between the particle and the wall is given by:

$$
F_{\mathrm{a}}=\frac{A D_{\mathrm{p}}}{12 \mathrm{z}_{\mathrm{e}}{ }^{2}},
$$

where $A$ is a Hamaker constant, $D_{\mathrm{p}}$ is the diameter of the primary particle and $z_{\mathrm{e}}$ is the separation gap between contact bodies including the effect of the contacting surface roughness.

The gravity moment $M_{\mathrm{g}}$ is represented by:

$$
M_{\mathrm{g}}=\frac{F_{\mathrm{g}} D_{\mathrm{ag}}}{2} \cos \theta
$$

The gravity $F_{\mathrm{g}}$ is given by:

$$
F_{\mathrm{g}}=\frac{\pi}{6} D_{\mathrm{ag}}^{3} \rho_{\mathrm{p}} \phi g
$$

where $\phi$ is the packing fraction of particles, $\rho_{\mathrm{p}}$ is the particle density and $g$ is the 
gravitational acceleration.

The aerodynamic drag moment $M_{\mathrm{d}}$ is approximated by $[7,15]$ :

$$
M_{\mathrm{d}} \approx 24 \tau_{\mathrm{w}} D_{\mathrm{ag}}^{3} \int_{0}^{1} Y^{2} \sqrt{Y(1-Y)} \mathrm{d} Y=\frac{15 \pi}{16} \tau_{\mathrm{w}} D_{\mathrm{ag}}^{3},
$$

where $\tau_{\mathrm{w}}$ is the wall shear stress caused by the airflow and $Y$ is the dimensionless distance from the surface. The wall shear stress $\tau_{\mathrm{w}}$ is given by [15]:

$$
\tau_{\mathrm{w}}=0.0396 \rho_{\mathrm{f}} v_{\mathrm{f}}^{1 / 4} D_{\mathrm{t}}^{-1 / 4} \bar{u}^{-7 / 4}
$$

where $\rho_{\mathrm{f}}$ is the air density, $v_{\mathrm{f}}$ is the kinematic viscosity and $D_{\mathrm{t}}$ is the tube diameter.

The moment caused by particle collision $M_{\mathrm{c}}$ is represented by:

$$
M_{\mathrm{C}}=\frac{F_{\mathrm{C}} D_{\mathrm{ag}}}{2} \cos \theta \text {. }
$$

The maximum collision force based on Hertz theory $F_{\mathrm{c}}$ is given by [27]:

$$
F_{\mathrm{C}}=1.12 k^{-2 / 5} m^{3 / 5} D^{1 / 5} v^{6 / 5},
$$

in which $k=\left(1-v_{1}^{2}\right) / E_{1}+\left(1-v_{2}^{2}\right) / E_{2}, m=m_{1} m_{2} /\left(m_{1}+m_{2}\right), D=D_{1} D_{2} /\left(D_{1}+D_{2}\right), v$ is the particle collision velocity, $v$ is the Poisson's ratio, $E$ is the Young's modulus, $m$ is the mass, $D$ is the diameter, and subscripts 1 and 2 refer to the two colliding bodies (here, aerosol particle and aggregate, respectively).

The moment caused by wall vibration $M_{\mathrm{v}}$ is represented by:

$$
M_{\mathrm{v}}=\frac{F_{\mathrm{v}} D_{\mathrm{ag}}}{2} \sin \theta
$$

The force arising from wall vibration $F_{\mathrm{v}}$ is given by:

$$
F_{\mathrm{v}}=\frac{\pi}{6} D_{\mathrm{ag}}^{3} \rho_{\mathrm{p}} \phi \alpha_{\mathrm{n} 0},
$$

where $\alpha_{\mathrm{n} 0}$ is the amplitude of vibration acceleration.

The critical condition based on the moment balance is represented by:

$$
M_{\mathrm{d}}+M_{\mathrm{C}}+M_{\mathrm{v}}=M_{\mathrm{a}}+M_{\mathrm{g}}
$$


Taking into account the conditions in our experiment, we simplified (11) to the following equation because $M_{\mathrm{g}}$ and $M_{\mathrm{d}}$ are relatively small:

$$
M_{\mathrm{C}}+M_{\mathrm{V}}=M_{\mathrm{a}} \cdot
$$

Solving (12) for the critical flow velocity $\bar{u}_{\mathrm{cp}}$ at which the aggregate can be reentrained from the surface gives (see Appendix):

$$
\bar{u}_{\mathrm{cp}}=\left(k_{1} D_{\mathrm{p}}^{-11 / 5}-k_{2} D_{\mathrm{p}}^{-1 / 5} \alpha_{\mathrm{n} 0}\right)^{10 / 21} \text {, }
$$

where:

$$
k_{1}=24.3 A z_{\mathrm{e}}^{-2} v_{\mathrm{f}}^{9 / 10} D_{\mathrm{t}}^{3 / 10} k^{2 / 5} \rho_{\mathrm{p}}^{-3 / 5} \phi^{-3 / 5} k_{0}{ }^{-16 / 5}\left(1+k_{0}{ }^{3} \phi\right)^{3 / 5}\left(1+k_{0}\right)^{1 / 5} \tan \theta,
$$

and:

$$
k_{2}=76.3 v_{\mathrm{f}}{ }^{9 / 10} D_{\mathrm{t}}{ }^{3 / 10} k^{2 / 5} \rho_{\mathrm{p}}{ }^{2 / 5} \phi^{2 / 5} k_{0}{ }^{-1 / 5}\left(1+k_{0}{ }^{3} \phi\right)^{3 / 5}\left(1+k_{0}\right)^{1 / 5} \tan \theta \text {. }
$$

For a non-vibrating wall, the critical flow velocity $\bar{u}_{\text {cp }}$ can be estimated by substituting $\alpha_{\mathrm{n} 0}=0$ into (13). The calculated results for the velocity are shown in Fig. 7. The constants used in the calculation are listed in Table 1. The experimental results for the critical flow velocity shown in Fig. 2 are also plotted in Fig. 7. The experimental results agree well with the calculated ones.

Figure 8 shows the relationship between the critical flow velocity $\bar{u}_{\text {cp }}$ and the amplitude of vibration acceleration $\alpha_{\mathrm{n} 0}$ as a parameter of the mass median diameter of particles. The critical flow velocity decreases with increasing vibration acceleration and/or particle diameter. For a much higher value of vibration accceleration, e.g. ultrasonic vibration [28] if applied, the particle deposition layer can be more easily removed. The experimental results agree well with the calculated ones, i.e. the critical 
flow velocity for no particle layer formation under wall vibration is well explained by the present model.

\section{CONCLUSIONS}

The simultaneous phenomenon of particle deposition and reentrainment in aerosol tube flow has been studied. In particular, the effect of the wall vibration on the particle deposition layer was discussed in detail. The results obtained here are summarized as follows.

(i) The state of the particle deposition layer is classified into a filmy deposition layer and a striped deposition layer.

(ii) The wall vibration is effective in enhancing the particle reentrainment. However, if the total separation strength is rather weak, the amount of deposited particles increases. This is because the wall vibration plays two opposite roles, i.e. (a) to increase the separation force and (b) to increase the particle deposition rate due to active capture of aerosol particles.

(iii) The critical flow velocity for no particle layer formation decreases with increasing vibration acceleration and/or particle diameter, which is well explained by the present moment balance model. 


\section{REFERENCES}

1. S. K. Friedlander and H. F. Johnstone, Deposition of suspended particles from turbulent gas streams, Ind. Engng. Chem. 49, 1151-1156 (1957).

2. J. W. Cleaver and B. Yates, A sublayer model for the deposition of particles from a turbulent flow, Chem. Engng. Sci. 30, 983-992 (1975).

3. P. G. Papavergos, and A. B. Hedley, Particle deposition behaviour from turbulent flows, Chem. Engng. Res. Des. 62, 275-295 (1984).

4. M. Fichman, C. Gutfinger and D. Pnueli, A model for turbulent deposition of aerosols, J. Aerosol Sci. 19, 123-136 (1988).

5. A. Li and G. Ahmadi, Deposition of aerosols on surfaces in a turbulent channel flow, Int. J. Engng Sci. 31, 435-451 (1993).

6. J. Young and A. Leeming, A theory of particle deposition in turbulent pipe flow, $J$. Fluid Mech. 340, 129-159 (1997).

7. Y. Kousaka, K. Okuyama and Y. Endo, Re-entrainment of small aggregate particles from a plane surface by air stream, J. Chem. Engng. Japan 13, 143-147 (1980).

8. H. C. Wang, Effects of Inceptive motion on particle detachment from surfaces, Aerosol Sci. Technol. 13, 386-393 (1990).

9. C.-J., Tsai, D. Y. H. Pui and B. Y. H. Liu, Particle detachment from disk surfaces of computer disk drives, J. Aerosol Sci. 22, 737-746 (1991).

10. H. Masuda. and S. Matsusaka, Particle Deposition and Reentrainment, in: Powder Technology Handbook, $2^{\text {nd }}$ edn. K. Gotoh, H. Masuda and K. Higashitani (Eds), pp. 143-154. Marcel Dekker, New York (1997).

11. G. Ziskind, M. Fichman and C. Gutfinger, Adhesion moment model for estimating 
particle detachment from a surface, J. Aerosol Sci. 28, 623-634 (1997).

12. J. W. Cleaver and B. Yates, Mechanism of detachment of colloidal particles from a flat substrate in a turbulent flow, J. Colloid Interface Sci. 44, 464-474 (1973).

13. M. W. Reeks, J. Reed and D. Hall, On the resuspension of small particles by a turbulent flow, J. Phys. D: Appl. Phys. 21, 574-589 (1988).

14. H. Y. Wen and G. Kasper, On the kinetics of particle reentrainment from surfaces, J. Aerosol Sci. 20, 483-498 (1989).

15. S. Matsusaka and H. Masuda, Particle reentrainment from a fine powder layer in a turbulent air flow, Aerosol Sci. Technol. 24, 69-84 (1996).

16. G. Ziskind, M. Fichman and C. Gutfinger, Resuspension of particulates from surfaces to turbulent flows - review and analysis, J. Aerosol Sci., 26 613-644 (1995).

17. J. W. Cleaver and B. Yates, The effect of re-entrainment on particle deposition, Chem. Engng. Sci. 31, 147-151 (1976).

18. M. W. Reeks and D. Hall. Deposition and resuspension of gas-borne particles in recirculating turbulent flows, J. Fluids Engng. 110, 165-171 (1988).

19. S. Matsusaka, M. Shimizu and H. Masuda, Formation of wall particle layers by simultaneous deposition and reentrainment of fine particles in turbulent aerosol flows, Kagaku Kogaku Ronbunshu 19, 251-257 (1993).

20. I. Adhiwidjaja, S. Matsusaka. and H. Masuda, Mechanism of formation of particle deposition layers by an aerosol flow, Kagaku Kogaku Ronbunshu 22, 127-133 (1996).

21. I. Adhiwidjaja, S. Matsusaka., T. Hamamura and H. Masuda, The effect of particle size on the movement of a striped pattern deposition layer in an aerosol flow, $J$. 
Soc. Powder Technol., Japan 34, 913-918 (1997).

22. S. Matsusaka, I. Adhiwidjaja, T. Nishio and H. Masuda, Formation of striped pattern deposition layers by an aerosol flow —analysis of thickness and interval of layers, Advanced Powder Technol. 9, 207-218 (1998).

23. I. Adhiwidjaja, S. Matsusaka, H. Tanaka and H. Masuda, Simultaneous phenomenon of particle deposition and reentrainment: Effects of surface roughness on deposition layer of striped pattern, Aerosol Sci. Technol. 33, 323-333 (2000).

24. S. Matsusaka, W. Theerachaisupakij, K. Tanoue and H. Masuda, Numerical simulation of particle trajectory in relation to the formation of a striped pattern deposition layer, J. Chem. Engng. Japan 34, 333-339 (2001).

25. S. Matsusaka, W. Theerachaisupakij, H. Yoshida and H. Masuda, Deposition layers formed by a turbulent aerosol flow of micron and sub-micron particles, Powder Technol. 118, 130-135 (2001).

26. I. Adhiwidjaja, S. Matsusaka, S. Yabe and H. Masuda, Simultaneous phenomenon of particle deposition and reentrainment in charged aerosol flow - effects of particle charge and external electric field on the deposition layer, Advanced Powder Technol. 11, 221-233 (2000).

27. M. Ghadiri, Particle impact and attrition. In: Powder Technology Handbook, $2^{\text {nd }}$ edn. K. Gotoh, H. Masuda and K. Higashitani (Eds), pp. 183-184, Marcel Dekker, New York (1997).

28. S. Matsusaka, M. Urakawa and H. Masuda, Micro-feeding of fine powders using a capillary tube with ultrasonic vibration, Advanced Powder Technol. 6, 283-293 (1995). 


\section{APPENDIX (DERIVATIONOF (13)-(15))}

$$
\begin{aligned}
& D_{1}=D_{\mathrm{p}}, D_{2}=D_{\mathrm{ag}}=k_{0} D_{\mathrm{p}} . \\
& \therefore D=\frac{D_{1} D_{2}}{D_{1}+D_{2}}=\frac{k_{0}}{1+k_{0}} D_{\mathrm{p}} . \\
& m_{1}=\frac{\pi}{6} D_{\mathrm{p}}^{3} \rho_{\mathrm{p}}, m_{2}=\frac{\pi}{6}\left(k_{0} D_{\mathrm{p}}\right)^{3} \rho_{\mathrm{p}} \phi . \\
& \therefore m=\frac{m_{1} m_{2}}{m_{1}+m_{2}}=\frac{k_{0}^{3} \phi}{1+k_{0}^{3} \phi} \frac{\pi}{6} D_{\mathrm{p}}^{3} \rho_{\mathrm{p}} . \\
& \tau_{\mathrm{w}}=\mu \frac{d u}{d y}=\mu \frac{2 v}{k_{0} D_{\mathrm{p}}} . \\
& \therefore v=\frac{\tau_{\mathrm{w}} k_{0} D_{\mathrm{p}}}{2 \mu}=0.0198 v_{\mathrm{f}}-3 / 4 D_{\mathrm{t}}^{-1 / 4} u^{-7 / 4} k_{0} D_{\mathrm{p}} .
\end{aligned}
$$

From (A.1)- (A.3), (7), and (8),

$$
\begin{aligned}
M_{\mathrm{C}} & =\frac{1.12}{2} k^{-2 / 5}\left(\frac{k_{0}^{3} \phi}{1+k_{0}^{3} \phi} \frac{\pi}{6} D_{\mathrm{p}}^{3} \rho_{\mathrm{p}}\right)^{3 / 5}\left(\frac{k_{0}}{1+k_{0}} D_{\mathrm{p}}\right)^{1 / 5}\left(0.0198 v_{\mathrm{f}}-3 / 4 D_{\mathrm{t}}^{-1 / 4} u^{-7 / 4} k_{0} D_{\mathrm{p}}\right)^{6 / 5} D_{\mathrm{ag}} \cos \theta \\
& =0.00343 v_{\mathrm{f}}{ }^{-9 / 10} D_{\mathrm{t}}{ }^{-3 / 10} u^{-21 / 10} k^{-2 / 5} \rho_{\mathrm{p}}{ }^{3 / 5} \phi^{3 / 5} k_{0}{ }^{21 / 5} D_{\mathrm{p}}{ }^{21 / 5}\left(1+k_{0}{ }^{3} \phi\right)^{-3 / 5}\left(1+k_{0}\right)^{-1 / 5} \cos \theta .
\end{aligned}
$$

From (1) and (2),

$$
M_{\mathrm{a}}=\frac{A D_{\mathrm{p}}}{12 z_{\mathrm{e}}^{2}} D_{\mathrm{ag}} \sin \theta=\frac{A k_{0} D_{\mathrm{p}}^{2}}{12 \mathrm{z}_{\mathrm{e}}^{2}} \sin \theta .
$$

From (9) and (10),

$$
M_{\mathrm{v}}=\frac{\pi}{12} D_{\mathrm{ag}}^{4} \rho_{\mathrm{p}} \phi \alpha_{\mathrm{n} 0} \sin \theta=\frac{\pi}{12} k_{0}{ }^{4} D_{\mathrm{p}}^{4} \rho_{\mathrm{p}} \phi \alpha_{\mathrm{n}_{0}} \sin \theta .
$$


Substituting (A.4)-(A.6) into (12),

$$
\begin{aligned}
& 0.00343 v_{\mathrm{f}}{ }^{-9 / 10} D_{\mathrm{t}}{ }^{-3 / 10} \bar{u}_{\mathrm{cp}}{ }^{21 / 10} k^{-2 / 5} \rho_{\mathrm{p}}{ }^{3 / 5} \phi^{3 / 5} k_{0}{ }^{21 / 5} D_{\mathrm{p}}{ }^{21 / 5}\left(1+k_{0}{ }^{3} \phi\right)^{-3 / 5}\left(1+k_{0}\right)^{-1 / 5} \cos \theta \\
& +\frac{\pi}{12} k_{0}{ }^{4} D_{\mathrm{p}}^{4} \rho_{\mathrm{p}} \phi \alpha_{\mathrm{n} 0} \sin \theta=\frac{A k_{0} D_{\mathrm{p}}{ }^{2}}{12 z_{\mathrm{e}}{ }^{2}} \sin \theta
\end{aligned}
$$

Hence,

$$
\bar{u}_{\mathrm{cp}}=\left(k_{1} D_{\mathrm{p}}^{-11 / 5}-k_{2} D_{\mathrm{p}}^{-1 / 5} \alpha_{\mathrm{n} 0}\right)^{10 / 21} \text {, }
$$

where

$$
k_{1}=24.3 A z_{\mathrm{e}}{ }^{-2} v_{\mathrm{f}}{ }^{9 / 10} D_{\mathrm{t}}{ }^{3 / 10} k^{2 / 5} \rho_{\mathrm{p}}{ }^{-3 / 5} \phi^{-3 / 5} k_{0}{ }^{-16 / 5}\left(1+k_{0}{ }^{3} \phi\right)^{3 / 5}\left(1+k_{0}\right)^{1 / 5} \tan \theta \text {, }
$$

and

$$
k_{2}=76.3 v_{\mathrm{f}}^{9 / 10} D_{\mathrm{t}}^{3 / 10} k^{2 / 5} \rho_{\mathrm{p}}{ }^{2 / 5} \phi^{2 / 5} k_{0}{ }^{-1 / 5}\left(1+k_{0}{ }^{3} \phi\right)^{3 / 5}\left(1+k_{0}\right)^{1 / 5} \tan \theta .
$$


Table 1 Constants for calculation.

\begin{tabular}{lr}
\hline$A(\mathrm{~J})$ & $2 \times 10^{-19}$ \\
$D_{\mathrm{t}}(\mathrm{m})$ & $6 \times 10^{-3}$ \\
$k(1 / \mathrm{Pa})$ & $0.1^{*}$ \\
$k_{0}\left(=D_{\mathrm{ag}} / D_{\mathrm{p}}\right)(-)$ & 2 \\
$z_{\mathrm{e}}(\mathrm{m})$ & $5.5 \times 10^{-9}$ \\
$\tan \theta(-)$ & 0.3 \\
$v_{\mathrm{f}}\left(\mathrm{m}^{2} / \mathrm{s}\right)$ & $1.55 \times 10^{-5}$ \\
$\rho_{\mathrm{p}}\left(\mathrm{kg} / \mathrm{m}^{3}\right)$ & $4 \times 10^{3}$ \\
$\phi(-)$ & 0.25 \\
\hline$* k \approx\left(1-v_{2}^{2}\right) / E_{2}$ for soft aggregate
\end{tabular}




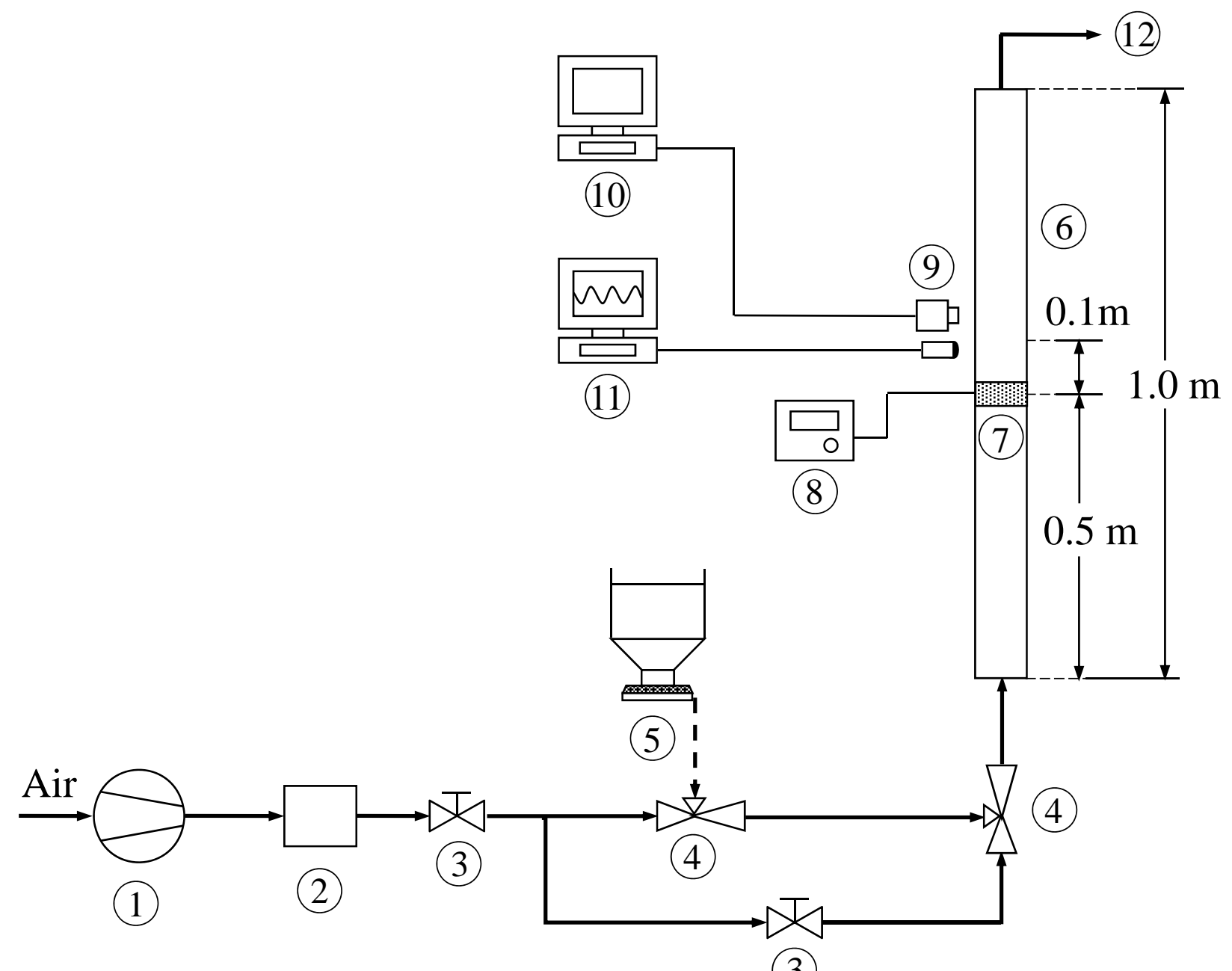

(1) Compressor

(7) Vibration motor

(2) Air dryer

(8) Electric supply

(3) Valve

(9) Digital video camera

(4) Ejector

(5) Table feeder

(10) Computer and monitor

(6) Glass tube

(11) Laser Doppler analyzer

(12) Bag filter

Figure 1. Experimental apparatus. 


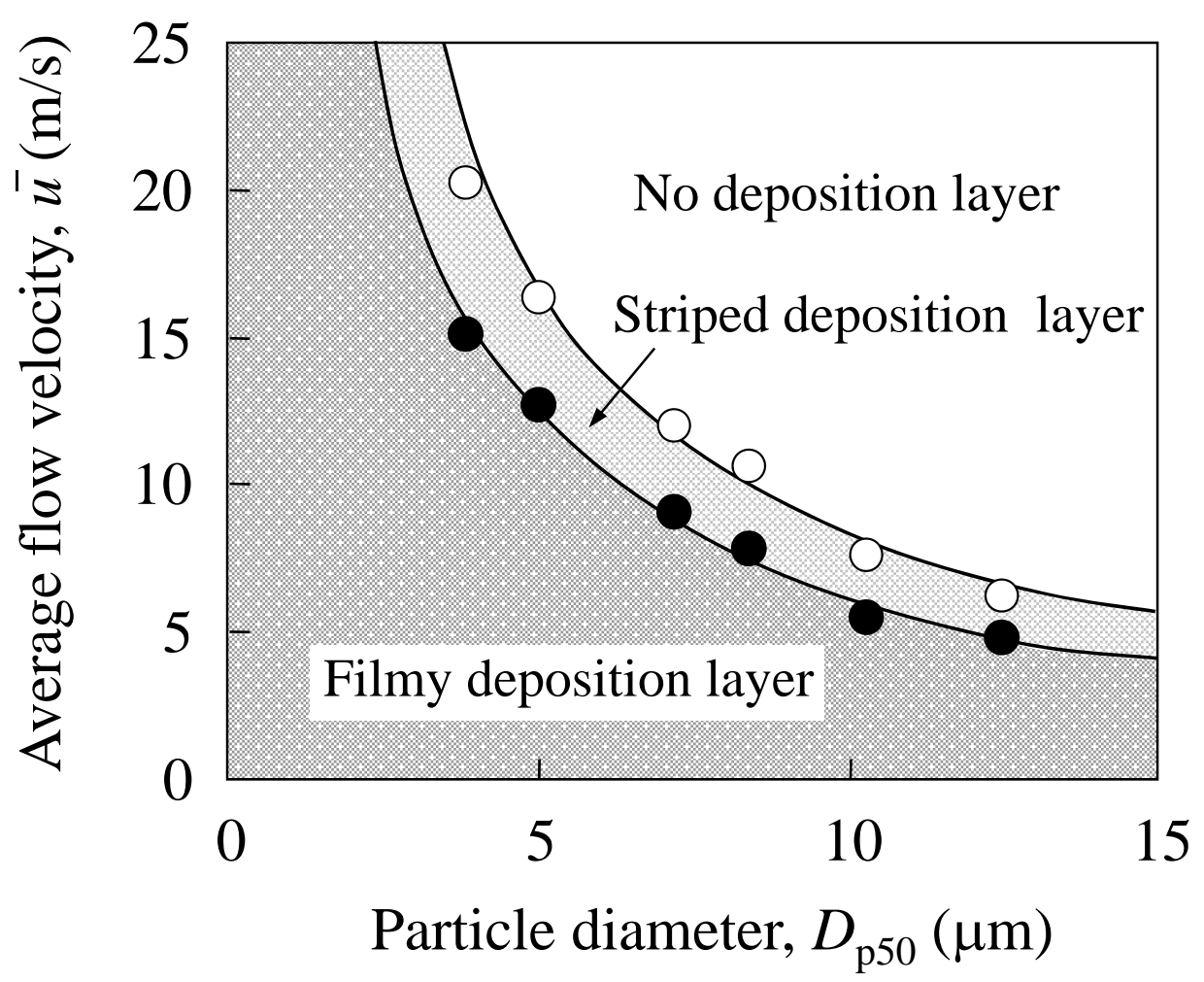

Figure 2. Constitutional diagram of particle deposition layer as a function of average flow velocity and particle diameter $(t=1200 \mathrm{~s})$. 

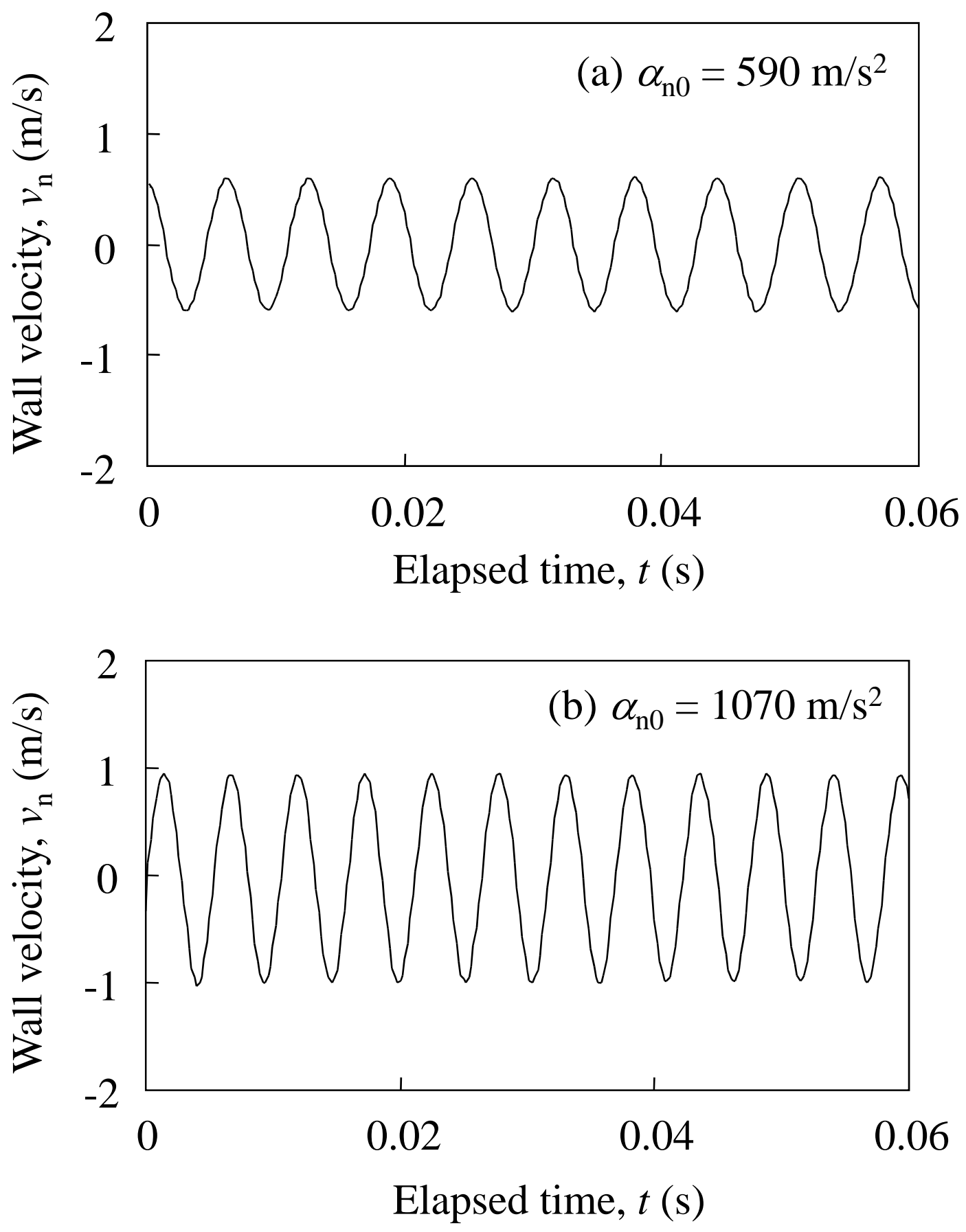

Figure 3. Typical waveforms of wall vibration velocity traced with the laser Doppler analyzer. 
(a) $\alpha_{\mathrm{n} 0}=590 \mathrm{~m} / \mathrm{s}^{2}$

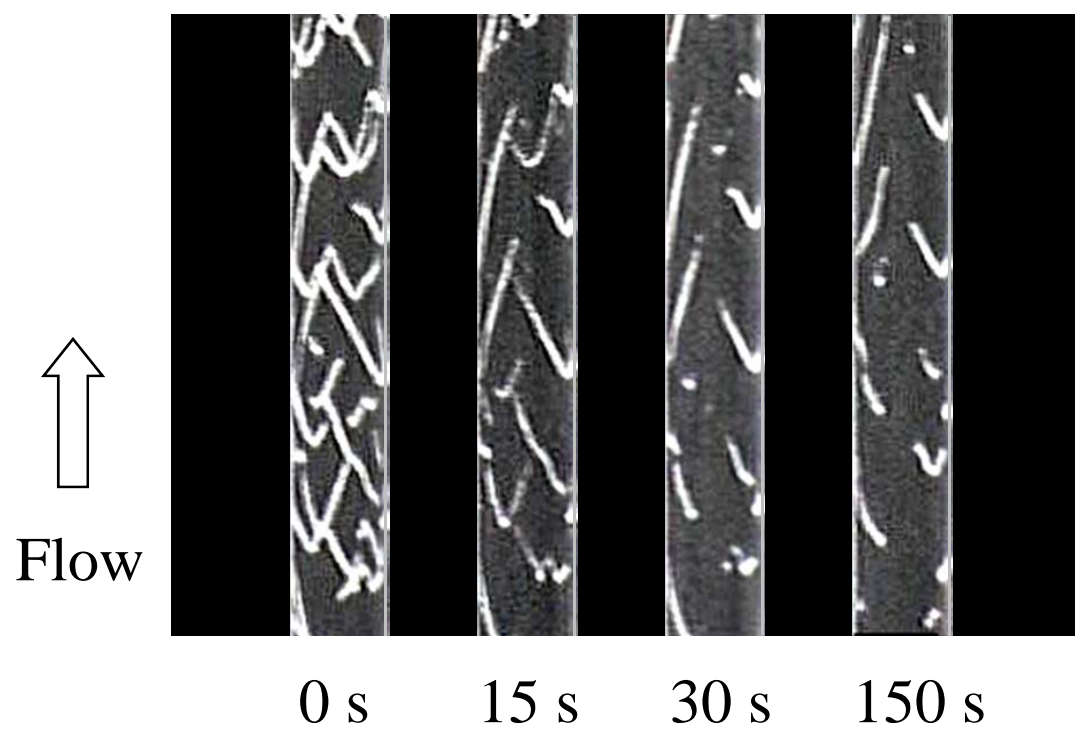

(b) $\alpha_{\mathrm{n} 0}=1070 \mathrm{~m} / \mathrm{s}^{2}$

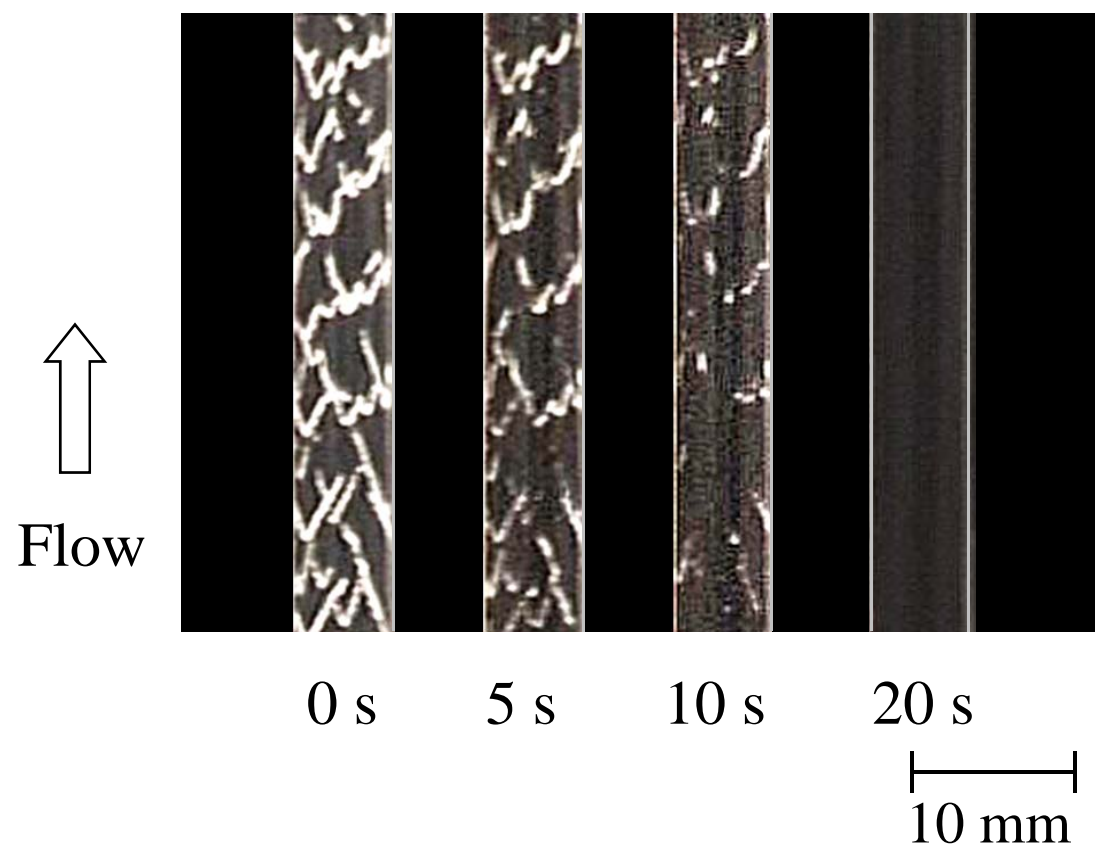

Figure 4. Effect of vibration acceleration on the striped deposition layer $\left(D_{\mathrm{p} 50}=10.3 \mu \mathrm{m}, \bar{u}=5.6 \mathrm{~m} / \mathrm{s}\right)$. 
(a) $\bar{u}=16.1 \mathrm{~m} / \mathrm{s}$

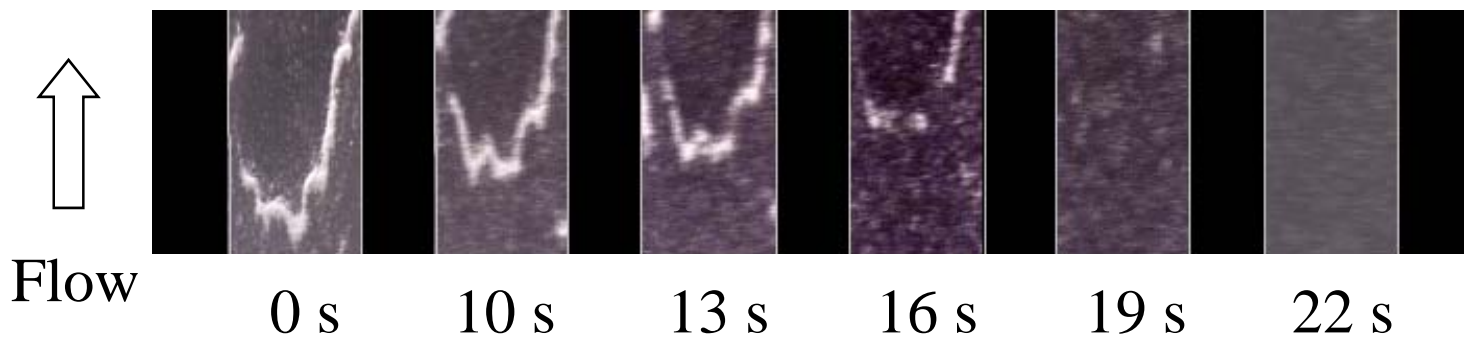

(b) $\bar{u}=14.4 \mathrm{~m} / \mathrm{s}$

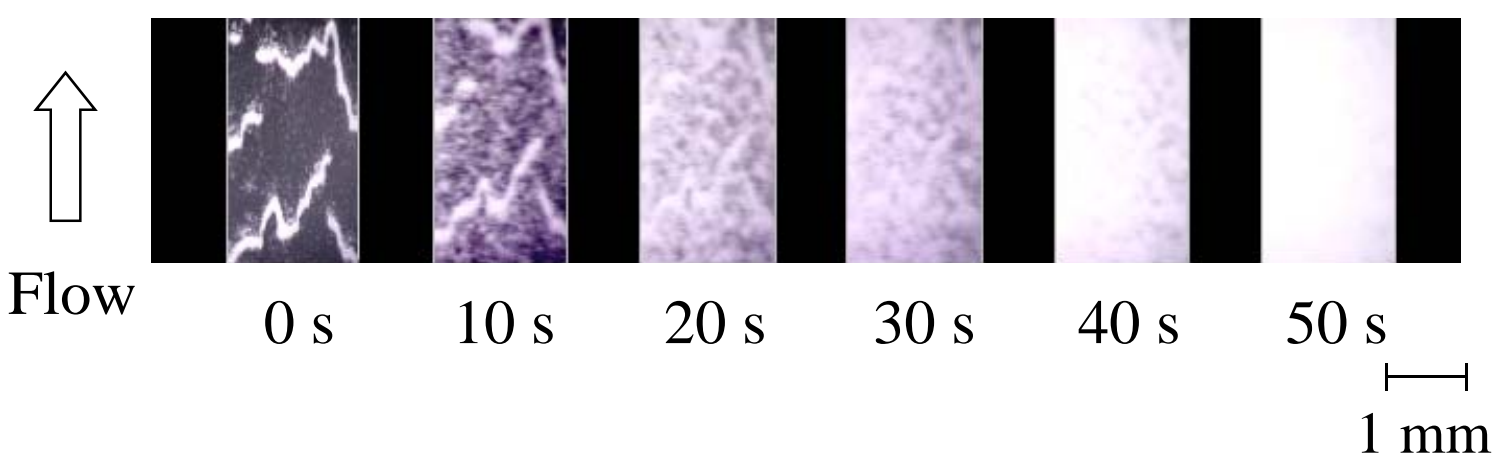

Figure 5. Particle deposition layers on the vibrating wall at different flow velocities $\left(D_{\mathrm{p} 50}=5.0 \mu \mathrm{m}, \alpha_{\mathrm{n} 0}=1070 \mathrm{~m} / \mathrm{s}^{2}\right)$. 


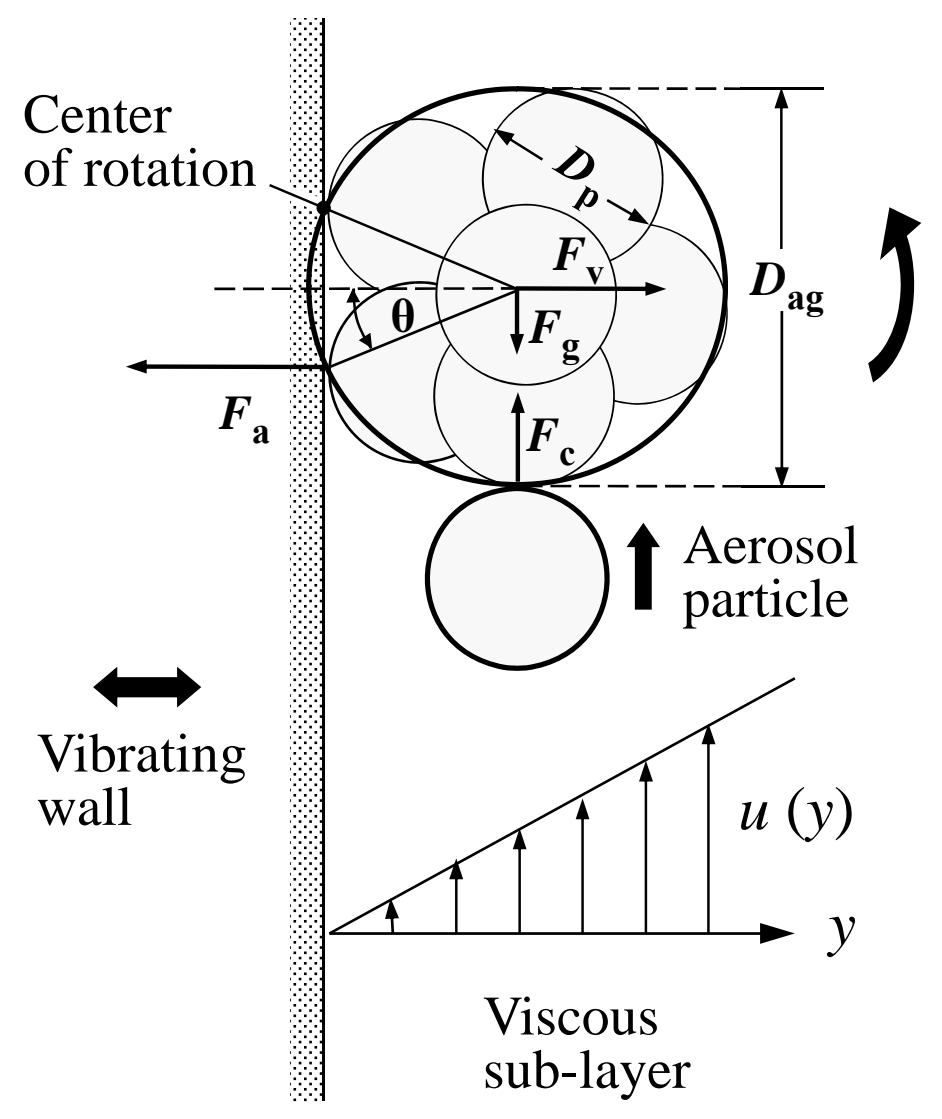

Figure 6. Diagram of forces acting on an aggregate. 


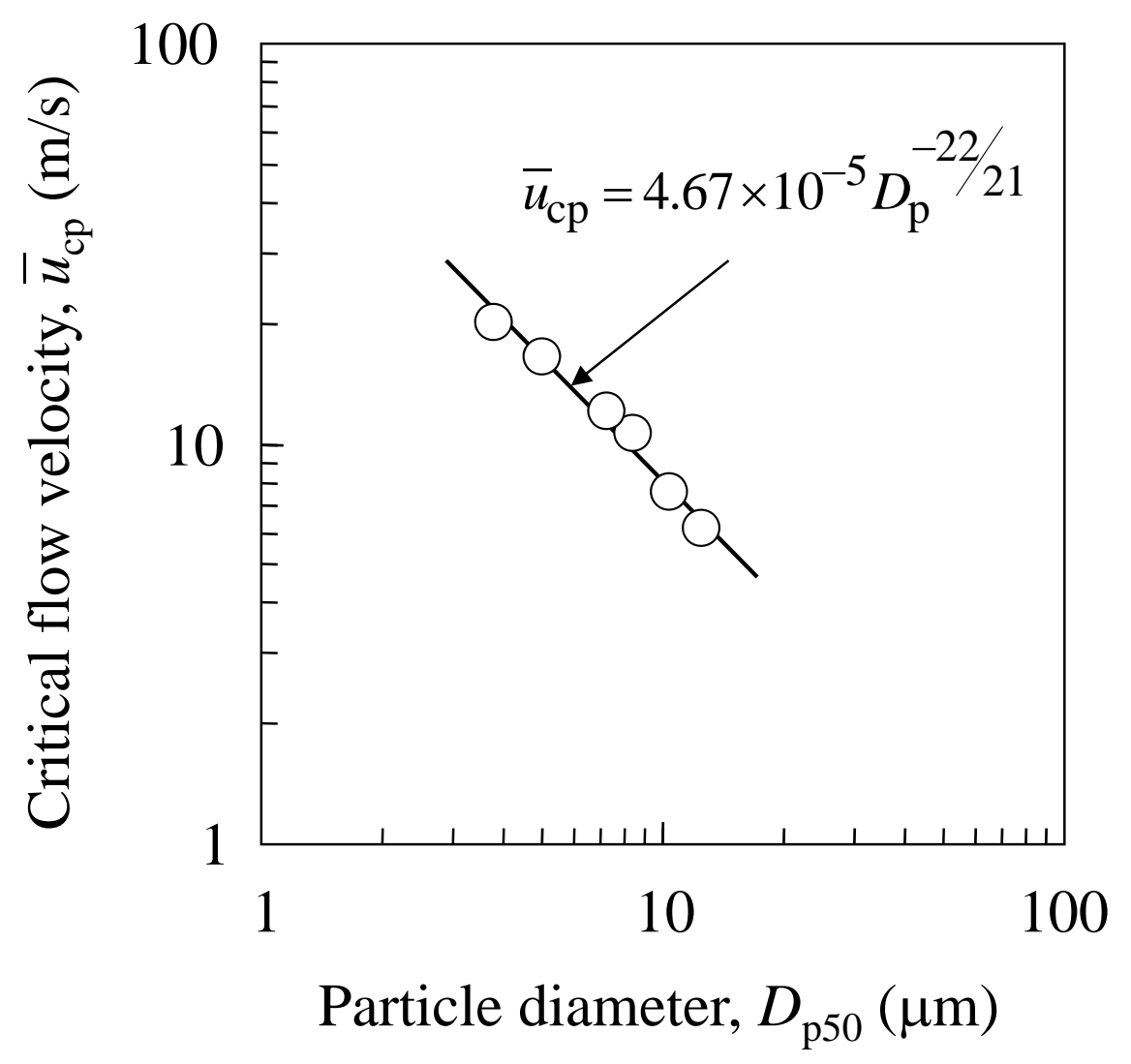

Figure 7. Critical flow velocity for no particle-layer formation on non-vibrating wall. 


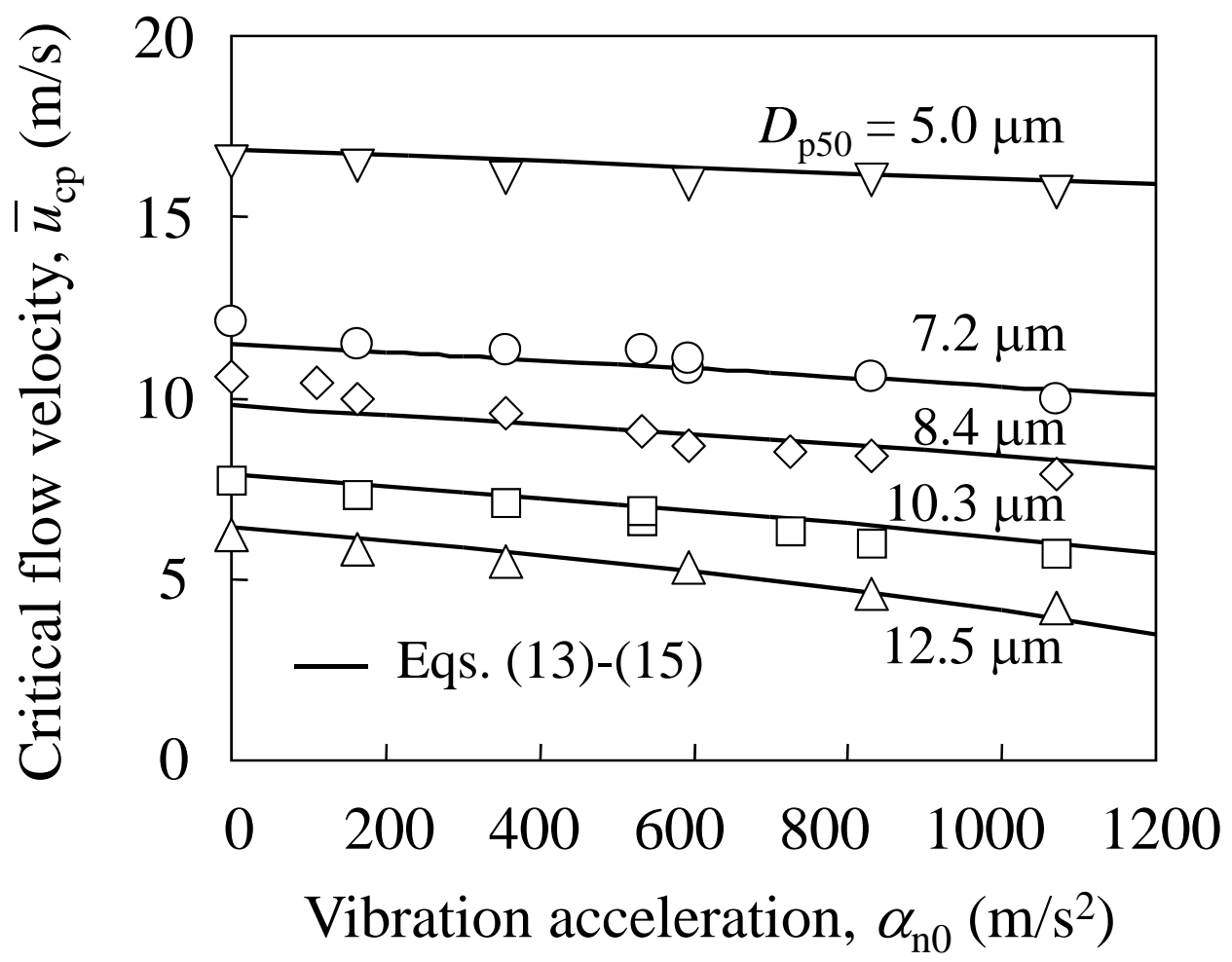

Figure 8. Effect of vibration acceleration on the critical flow velocity for no particle-layer formation $\left(k_{1}=8.06 \times 10^{-10}\left(\mathrm{~m}^{43 / 10} / \mathrm{s}^{21 / 10}\right), k_{2}=3.06 \times 10^{-3}\left(\mathrm{~m}^{13 / 10} / \mathrm{s}^{1 / 10}\right)\right.$ (see Table 1)). 